\title{
UNSUR INTRINSIK NOVEL AROMA KARSA KARYA DEE LESTARI DAN PEMANFAATANNYA SEBAGAI MATERI AJAR SASTRA DI KELAS XII SMA
}

\author{
Bagus Juniarto Wibowo, Andayani, Sri Hastuti \\ Universitas Sebelas Maret \\ Email: bagjuniarto@gmail.com
}

\begin{abstract}
Abstrak: Penelitian ini bertujuan untuk mendeskripsikan (1) unsur intrinsik (alur, tema, amanat, tokoh dan penokohan, latar, serta sudut pandang) dalam novel Aroma Karsa karya Dee Lestari; (2) hubungan antarunsur intrinsik dalam novel Aroma Karsa karya Dee Lestari; (3) pemanfaatan analisis struktural pada novel Aroma Karsa karya Dee Lestari sebagai materi ajar sastra kelas XII SMA. Jenis penelitian ini adalah penelitian deskriptif kualitatif, menggunakan pendekatan struktural sastra. Sumber data dalam penelitian ini adalah dokumen novel Aroma Karsa karya Dee Lestari. Teknik pengambilan sampel menggunakan metode purposive sampling. Teknik pengumpulan data yang digunakan yaitu dengan cara analisis dokumen dan wawancara. Peneliti menggunakan triangulasi teori dan sumber data sebagai uji validitas data. Teknik analisis data yang digunakan dalam penelitian ini adalah teknik analisis model interaktif. Hasil penelitian ini dapat dikemukakan bahwa (1) terdapat unsur intrinsik novel Aroma Karsa karya Dee Lestari meliputi tema, alur, penokohan, latar, sudut pandang, dan amanat; (2) setiap unsur yang terdapat dalam novel Aroma Karsa karya Dee Lestari memiliki hubungan dan tidak dapat berdiri sendiri; (3) novel Aroma Karsa karya Dee Lestari dapat dimanfaatkan sebagai materi ajar sastra kelas XII SMA pada KD 3.9 menggunakan metode Jigsaw, Talking sticking, dan lain-lain.
\end{abstract}

Kata Kunci: novel, struktural, unsur intrinsik, materi ajar sastra.

\section{INTRINSIC ELEMENTS IN THE NOVEL OF “AROMA KARSA" BY DEE LESTARI AND THE UTILIZATION AS A LITERATURE TEACHING MATERIAL IN TWELVE GRADE OF SENIOR HIGH SCHOOL}

\begin{abstract}
The research aims to describe (1) intrinsic elements (plot, themes, orders, figures and luminaries, backgrounds, and viewpoints) on the novel "Aroma Karsa" by Dee Lestari; (2) the intrinsic relationship to the novel "Aroma Karsa" by Dee Lestari; (3) utilizing the structural analysis on the novel "Aroma Karsa" by Dee Lestari as a literature teaching material of class twelve senior high school. This type of research is a qualitative descriptive study, using a structural approach to literature. The data source in this study is a document of Dee Lestari's "Aroma Karsa" novel. Sampling techniques using the purposive sampling method. The data collection techniques used are by means of document analysis and interviews. Researchers use triangulation theory and data sources as a data validity test. The data analysis techniques used in this research are interactive model analysis techniques. The results of this research can be suggested that (1) there are intrinsic elements of the novel "Aroma Karsa" by Dee Lestari include themes, grooves, backgrounds, settings, viewpoints, and orders; (2) every element in the novel "Aroma Karsa" by Dee Lestari has a relationship and can not stand alone; (3) the Novel "Aroma
\end{abstract}

BASASTRA Jurnal Bahasa, Sastra, dan Pengajarannya

Volume 9 Nomor 1, April 2021, P-ISSN 2302-6405, 2E-ISSN 2714-9765 
Karsa" by Dee Lestari can be used as a literature teaching material of class twelve senior high school using the methods of Jigsaw, Talking Sticking and others.

Keyword: novel, structural, intrinsic elements, literature teaching materials.

\section{PENDAHULUAN}

Sastra adalah hasil serta bagian dari kenyataan yang ada di masyarakat. Hal tersebut sejalan dengan pendapat Leenhart (1967: 530) dalam Prameswari yang menyatakan bahwa "literature is a product as well as part of the social reality of society" yang memiliki arti bahwa sastra adalah produk sekaligus bagian dari realitas sosial di masyarakat (Prameswari, Waluyo, \& Waluyo, 2018). Selain itu, sastra identik dengan ungkapanungkapan yang 'tidak bisa terungkapkan' (Emzir, 2016). Hal tersebut menjadikan sebuah permasalahan yang sering muncul dalam pembahasan karya prosa fiksi termasuk novel. Sependapat dengan itu, Nurgiyantoro mengatakan bahwa penyebab sulitnya seseorang menafsirkan karya sastra dikarenakan sebuah karya sastra (novel) merupakan karya yang tersusun oleh struktur yang lengkap, unik, dan tidak langsung. Maka dari itu, diperlukan sebuah upaya untuk dapat menjelaskan melalui proses telaah atau analisis demi menjelaskan permasalahan dengan disertai bukti analisis yang akurat (Nurgiyantoro, 2012). Upaya yang dapat dilakukan untuk memahami karya sastra adalah melalui pendekatan struktural sastra. Pendekatan struktural dilakukan karena Nurgiyantoro mengatakan bahwa karya fiksi terbangun dari totalitas dan keutuhan makna yang secara koherensif tersusun oleh berbagai unsur yang menjadi pokok kajian struktural. Selain itu, novel sebagai sebuah karya fiksi menawarkan dunia yang berisi model kehidupan yang diidealkan, dunia imajinatif yang dibangun melalui berbagai unsur instrinsiknya, seperti tema, tokoh dan penokohan, latar, alur, sudut pandang, serta amanat yang memerlukan daya pemahaman penuh untuk memaknainya (Nurgiyantoro, 2012).

Berdasarkan penelitian yang dilakukan oleh Yanti \& May (2016) menunjukkan bahwa terdapat korelasi positif antara analisis struktural atau analisis unsur intrinsik novel dengan kemampuan memahami isi novel terhadap hasil belajar apresiasi sastra siswa SMA. Penelitian tersebut mengungkapkan bahwa kemampuan memahami unsur intrinsik dan kemampuan memahami isi novel secara bersama-sama mempunyai korelasi dengan hasil belajar apresiasi sastra. Hal ini menunjukkan korelasi yang parsial antara variabel kemampuan memahami unsur intrinsik dan kemampuan memahami isi novel secara bersama-sama mempunyai korelasi pula dengan hasil belajar apresiasi sastra. Oleh karena itu, berdasarkan hasil penelitian tersebut 
peneliti tertarik memilih kajian struktural dalam mengkaji karya sastra berupa novel agar dapat membantu pembaca memahami isi karya sastra. Tujuan dari analisis struktural sastra adalah untuk mengetahui dengan membedah dan menjelaskan dengan sangat cermat tentang keterkaitan antarkomponen intrinsik karya sastra sehingga mendapatkan makna yang utuh. Proses telaah analisis struktural bukanlah kegiatan penjumlahan komponen intrinsik karya sastra saja, melainkan mencari sumbangan besar yang diberikan komponen karya sastra pada keterkaitan dan keterjalinan makna yang menyeluruh (Teeuw dalam Jabrohim, 2014). Maka dari itu, kajian struktural tidak sekadar melakukan pendataan komponenkomponen intrinsiknya. Namun menunjukkan adanya hubungan antara komponen tersebut (Nurgiyantoro, 2012). Struktur teks sastra terutama novel merupakan bagian sangat penting karena tidak hanya sebuah ringkasan tetapi sebuah thread (benang) yang menyatukan. Pernyataan tersebut sejalan dengan kutipan dari Ali yang menyatakan "structure of a literary text especially novel is crucial as it is not merely a summary but a thread that brings together writer's perspective, critical evaluation, plot and other elements of the story, to make it easy for the readers to grasp the intentions of the writer" (Ali, 2014). Pernyataan Ali tersebut memiliki arti bahwa sastra (novel) memiliki struktur teks yang sangat penting untuk menyatukan berbagai perspektif, seperti perspektif penulis, kritikus, dan elemen-elemen lain yang bermaksud memudahkan pembaca untuk memahami maksud sastrawan.

Analisis struktural (novel) dilakukan melalui proses identifikasi, pengkajian, dan pendeskripsian manfaat dan keterkaitan antarkomponen intrinsik yang berkaitan. Dengan kata lain, hal terpenting dalam telaah struktural adalah menunjukkan hubungan antarkomponen intrinsik serta mencari pengaruh yang diberikan komponen tersebut terhadap keindahan dan keutuhan makna karya sastra. Melihat kenyataan yang terjadi dewasa ini, sudah saatnya pendidikan di Indonesia dibenahi tanpa meninggalkan jati diri bangsa Indonesia sehingga menciptakan generasi yang berkarakter. Hal tersebut sejalan dengan Peraturan Menteri Pendidikan dan Kebudayaan Republik Indonesia nomor 20 tahun 2018 tentang penguatan pendidikan karakter pada satuan pendidikan formal. Penguatan pendidikan karakter (PPK) menerapkan nilai-nilai pancasila yang meliputi, nilai-nilai religius, jujur, toleran, disiplin, bekerja keras, kreatif, mandiri, demokratis, rasa ingin tahu, semangat kebangsaan, cinta tanah air, menghargai prestasi, komunikatif, cinta damai, gemar membaca, peduli lingkungan, peduli sosial, dan bertanggung jawab. Salah satu novel terbaru yang menjadi gebrakan dunia 
sastra yang dapat memberikan pembelajaran dan nilai-nilai pendidikan karakter bagi siswa adalah novel Aroma Karsa mahakarya Dewi Lestari atau yang kerap disapa Dee Lestari. Mulanya, Aroma Karsa merupakan karya serial berbabak yang telah diterbitkannya secara digital. Setelah semua babaknya selesai, Aroma Karsa dipasarkan dalam bentuk cetak. Aroma Karsa merupakan novel yang mengedepankan permainan indra perasa yang jarang ditemui dalam buku lain. Novel Aroma Karsa yang diterbitkan oleh Bentang Pustaka tahun 2018 dikemas secara detail, dimulai dari pengenalan hingga akhir. Aroma Karsa juga merupakan hasil riset yang mendalam sebelum dituliskan. Artinya, Aroma Karsa merupakan fiksi yang ditulis berdasar fakta-fakta yang terkumpul dan terasa nyata. Penelitian struktural terhadap Aroma Karsa bertujuan untuk membantu siswa dalam memahami isi melalui pengungkapan komponenkomponen instrinsik yang ada dalam karya tersebut. Analisis struktural diambil menjadi fokus penelitian karena belum terdapat penelitian serupa dengan objek yang sama sebelumnya. Pembelajaran sastra sangat diperlukan guru sastra yang luas bacaannya serta terbuka untuk gejala sastra yang baru, yang dapat melakukan tugas dengan baik (Alwi, 2002). Teks sastra yang dipilih guru untuk diajarkan sebagai materi dalam pembelajaran sangat penting karena hal tersebut dapat memupuk kecerdasan siswa dalam berbagai aspek kehidupan. Oleh karena itu, pemilihan novel yang digunakan sebagai materi dalam pembelajaran pun tidak sembarangan. Novel yang dipilih sebagai materi ajar harus memenuhi kriteria tertentu, yakni dari segi bahasa yang indah dan mudah dipahami, menarik, terdapat nilai-nilai pendidikan, dan memengaruhi pembacanya untuk berbuat baik atau inspiratif. Dengan arti lain, melalui kegiatan apresiasi sastra dapat memupuk kecerdasan siswa (spiritual, emosional, dan intelektual). Siswa juga dilatih memahami isi karya sastra sehingga mampu menarik nilai yang ada.

Berdasar penjelasan di atas maka dalam pembelajaran sastra pada jenjang SMA sangat dibutuhkan penguasaan akan unsur-unsur karya sastra melalui analisis struktural demi memahami isi secara mendalam. Penguasaan unsur karya sastra akan menghasilkan makna utuh dan menyeluruh yang selaras dengan materi pembelajaran kurikulum 2013 pada siswa kelas XII SMA pada kompetensi dasar 3.9 mengenai analisis isi dan kebahasaan novel. Melalui penelitian ini guru diharapkan dapat memanfaatkan novel Aroma Karsa sebagai materi ajar analisis isi dan kebahasaan novel dalam pembelajaran sastra di sekolah. Oleh karena itu, peneliti berusaha melakukan penelitian mengenai novel Aroma Karsa dengan menggunakan 
pendekatan struktural sastra yang berjudul "Unsur Intrinsik Novel Aroma Karsa Karya Dee Lestari dan Pemanfaatannya sebagai Materi Ajar Sastra Kelas XII SMA”.

\section{METODE}

Penelitian ini menggunakan metode penelitian deskriptif kualitatif dengan pendekatan struktural sastra. Data yang digunakan dalam penelitian ini adalah kata-kata, kutipan atau hasil telaah dokumen novel Aroma Karsa karya Dee Lestari sesuai dengan rumusan masalah dalam penelitian ini. Sumber data yang digunakan dalam penelitian ini berupa dokumen, informan, buku teori dan jurnal. Peneliti menggunakan teknik pengampilan sampel dengan cara purposive sampling, yaitu melakukan teknik pengambilan sampel yang disesuaikan dengan tujuan penelitian. Peneliti melakukan teknik pengumpulan data dengan cara analisis dokumen dan wawancara. Analisis ini dilakukan dengan cara membaca novel Aroma Karsa karya Dee Lestari secara berulang. Data yang telah terkumpul diperiksa kevalidannya dengan teknik uji triangulasi. Teknik uji validitas data yang digunakan dalam penelitian ini adalah teknik triangulasi teori. Triangulasi teori menghindarkan terjadinya kesalahan interpretasi dengan cara memanfaatkan persepsi yang beragam, mengidentifikasi cara pandang yang berbeda-beda. Peneliti juga melakukan triangulasi sumber data untuk pengumpulan data melalui hasil wawancara. Wawancara dilakukan untuk mendapatkan data yang sama dan sejenis dari beberapa informan lalu membandingkannya. menggunakan model analisis data dengan model interaktif. Miles \& Huberman dalam (Emzir, 2014) menyebutkan bahwa terdapat tiga tahapan dalam analisis data model interaktif, yaitu reduksi data (data reduction), model data (data display), dan penarikan kesimpulan/verifikasi (verification).

\section{HASIL DAN PEMBAHASAN}

\section{Analisis Unsur-unsur Intrinsik Novel Aroma Karsa Karya Dee Lestari}

\section{Tema}

Tema utama (tema mayor) dalam novel Aroma Karsa adalah aroma. Aroma menjadi inti dalam masalah cerita. Aroma Karsa bercerita tentang pencarian sebuah bunga misterius yaitu Puspa Karsa. Hanya satu cara yang dapat menemukannya, yaitu dengan hidung yang mampu membauinya karena Puspa Karsa hanya akan mengeluarkan aroma ke orang tertentu.

Tema tambahan (tema minor) merupakan tema yang hanya ada di bagian-bagian cerita saja. Beberapa tema tambahan dalam novel Aroma Karsa, di antaranya: 
Misteri

Bagian awal dari novel ini dibuka oleh percakapan Janirah Prayagung dengan Raras Prayagung mengenai bunga yang luar biasa, yaitu Puspa Karsa. Berbekal dongeng dan lontar hasil curian Janirah di Keraton, cerita dan perjalanan mencari Puspa Karsa dimulai. Berdasar lontar tersebut memacu tekad dan ambisi Raras untuk menemukannya dan membuktikan kebenarannya. Melalui ekspedisi, misteri sedikit demi sedikit terbuka. Puspa Karsa merupakan tanaman sekaligus "seseorang". Puspa Karsa merupakan jelmaan dari Sang Hyang Batari Karsa.

Sesungguhnya Puspa Karsa merupakan jelmaan. Ia bisa menitis, termasuk ke Ambrik (ibu Suma). Sehingga mereka memiliki semacam ikatan. Ikatan itulah yang mampu mempertemukan mereka. Suma telah berhasil bertemu dengan ibu sebenarnya. Hati kecilnya berkata dengan kekuatan hubungan nurani darah anak dan ibu bahwa Puspa Karsa adalah ibunya. Puspa Karsa mengeluarkan bau yang memikat tidak hanya sekadar untuk diidentifikasi keberadaanya, melainkan agar ia dibebaskan dari sana. Tetapi, kebebasan Puspa Karsa dapat membuat bencana seluruh dunia. Oleh karena itu, Puspa Karsa sangat dijaga dan disembunyikan di Alas Kalingga. Puspa Karsa sangat berbahaya dan memanfaatkan manusia dengan cara menitis. Ambrik atau ibu Suma merupakan korbannya. Ia akan terus menitis ke keturunan perempuan. Hanya ada satu cara yang dapat dilakukan untuk menghentikan hal tersebut, yaitu Gurah Rudira.

Puspa Karsa ingin terus hidup dengan cara menitis. Girah Rudira harus dilakukan jika terdeteksi Puspa Karsa. Girah Rudira merupakan cara yang kejam di kehidupan manusia di bumi, yaitu dengan membius, kemudian tubuh digantung dengan posisi kepala di bawah dan kaki di atas. Kemudian menusuk leher dengan belati berulir dan menampung darah untuk dikeringkan. Darah dikeringkan agar penitisan gagal dalam darah Ambrik sudah mengalir Puspa Karsa. Demikianlah cara kejam untuk memberantas kekejaman Puspa Karsa (hlm. 608).

Sementara itu, selain misteri Puspa Karsa yang ternyata ada hubungannya dengan Suma (Malini). Terdapat pula misteri mengenai tokoh Jati.

Jati berasal dari Dwarapala. Jati bukanlah anak Anung yang diketahui demikian. Jati adalah anak hutan atau Wong Banaspati. Jati adalah Banaspati di Dwarapala dengan nama Randu.

Misteri-misteri berdasar kutipankutipan di atas melengkapi jalannya cerita dalam novel Aroma Karsa. Misteri sosok Jati yang sebenarnya adalah Randu, seorang Banaspati di Dwarapala. Sosok Suma yang sebenarnya adalah Malini, anak Anung 
dan Ambrik yang dibawa Raras dari Desa Dwarapala saat ekspedisi 1 mencari Puspa Karsa.

\section{Persekongkolan}

Tema persekongkolan dibawakan oleh tokoh Raras dengan Khalil. Khalil yang ikut membesarkan dan memberi pekerjaan Jati, dulunya merupakan tangan kanan Raras di Kemara. Jati telah menemukan fakta bahwa Khalil merupakan kaki tangan Kemara selama 26 tahun. Khalil juga merupakan orang yang terlibat dalam penculikan Suma dan Jati.

Khalil merupakan orang yang terlibat dan menyembunyikan keberadaan Anung, Ambrik, Jati, dan Suma. Ia tahu segalanya, tapi ia memilih untuk bungkam meskipun ia merupakan saksi awal kehidupan Jati. Bahkan ia bungkam selama 26 tahun meskipun selalu hidup bersamanya. Khalil mempekerjakan Jati di Attarwala miliknya. Khalil menjebak Jati hingga dia mendapat hukuman menjadi pegawai Kemara seumur hidup.

Tiruan parfum Attarwala kepada Kemara yang dilakukan oleh Jati disengaja oleh Khalil. Khalil meletakkan sampel Puspa Ananta dengan harapan Jati akan ingin tahu dan menirunya. Akhirnya, Jati terjebak dalam hal itu (hlm. 51).

Raras dan Khalil melakukan percakapan via telepon. Percakapan itu terjadi ketika Anung mulai ingat nama desanya. Hal itu sangat berbahaya dan memancing rasa ingin tahu Jati yang selama ini ditutupi oleh mereka. Datadata di atas merupakan bukti tema persekongkolan yang terjadi dalam Aroma Karsa.

\section{Kungkungan}

Terdapat beberapa kungkungan yang dialami beberapa tokoh dalam novel Aroma Karsa membuat tokoh tersebut ingin merasakan kebebasan. Kungkungan pertama terjadi dalam tokoh Janirah. Janirah yang merupakan anak dari abdi dalem punakawan jenjang terendah dari keluarganya. Selama tiga generasi tumbuh besar di lingkungan Keraton Yogyakarta kasta terendah membuatnya ingin terbebas dari kungkungan tersebut.

Upaya bebas dari kungkungan tersebut dilakukan Janirah dengan mencuri kotak besi sebesar kotak sepatu. Kotak tersebut berisi 3 tube perunggu sebesar buku jari yang jika digoyang terasa menampung cairan kental (hlm. 7). Raras yang mewarisi tube perunggu berisi cairan tersebut memanfaatkannya untuk terbebas dari kebangkrutan perusahaan Prayagung yang dipimpin oleh ayahnya. Akhirnya dia menggunakan kekuatan Puspa Karsa menyingkirkan Romo dari Kemara (hlm. 14-17). Selain itu, kungkungan nyata dialami oleh Puspa Karsa atau Sanghyang Batari Karsa. Ia merasa dikungkung di Alas Kalingga, walaupun ia sangat berbahaya jika ia bebas. Bukti upaya Puspa Karsa ingin bebas yaitu dengan segala cara dilakukannya. Puspa Karsa atau 
Sanghyang Batari Karsa adalah orang yang sangat kuat dan cerdas.

\section{Alur/Plot}

Novel Aroma Karsa secara umum memiliki alur progresif. Namun, terdapat beberapa bagian yang menunjukkan adegan sorot balik. Berikut uraian temuan mengenai alur yang terdapat dalam novel Aroma Karsa karya Dee Lestari.

\section{Paparan (Exposition)}

Paparan ialah awal dari cerita. Novel Aroma Karsa berawal dari kisah seorang Janirah Prayagung yang menjadi abdi dalem di Keraton Yogyakarta dan cucunya, Raras Prayagung. Cerita diawali ketika Janirah bercerita kepada Raras mengenai Puspa Karsa yang misterius. Dari cerita itulah, ambisi dan obsesi Raras berapi-api untuk mendapatkan Puspa Karsa.

\section{Rangsangan (Inciting moment)}

Tahap ini pengarang mulai menampakkan masalah-masalah yang kemudian dikembangkan ke arah peningkatan konflik. Dalam novel Aroma Karsa ini rangsangan muncul ketika Jati sebagai peracik parfum di Attarwala meniru produk unggulan perusahaan besar Kemara. Akibat Jati meniru produk Kemara, ia mendapat hukuman bekerja seumur hidup di Kemara untuk Raras Prayagung sebagai pengganti penjara Jati.

\section{Gawatan (Rising Action)}

Tahap ini pengarang mulai menimbulkan rangsangan terhadap konflik. Dalam novel Aroma Karsa tahap ini ditunjukkan ketika Jati hidup di Kemara dan ditentang keras oleh Suma, anak Raras.

\section{Tikaian (Conflict)}

Tahap ini pengarang menanjakkan rangsangan konflik menjadi sebuah konflik atau perkara. Dalam novel Aroma Karsa, tahap ini ditunjukkan ketika Suma mengusik dengan membuka catatan pribadi Jati hingga Jati marah dan meninggalkan rumah Raras.

\section{Rumitan (Complication)}

Tahap ini konflik semakin rumit. Dalam novel Aroma Karsa, kerumitan konflik tersebut ditunjukkan ketika Tim Ekspedisi sudah siap, tetapi ditentang oleh Mbah Jo dan beberapa peringatan alam yang ada.

\section{Klimaks (Climax)}

Tahap ini merupakan puncak dari konflik dan pertentanganpertentangan yang ada. Dalam novel Aroma Karsa hal ini ditunjukkan melalui cerita ketika Tim sudah berada di Gunung Lawu dan mendapat serangan-serangan dari makhluk Dwarapala. Beberapa orang menjadi korban.

\section{Leraian (falling action)}

Tahap ini pengarang mulai menurunkan konflik. Dalam novel 
ditunjukkan melalui cerita Jati, Suma, dan Lambang selamat dari Puspa Karsa.

\section{Selesaian (Denovement)}

Tahap ini merupakan bagian akhir cerita. Novel Aroma Karsa berakhir dengan terbunuhnya Raras oleh Suma karena pengaruh Puspa Karsa. Akhirnya, Suma dan Jati menjadi partner seumur hidup dan bertunangan.

\section{Penokohan}

Tokoh Utama

Aroma Karsa memainkan banyak tokoh dalam ceritanya. Tokohtokoh dalam novel Aroma Karsa dilukiskan melalui teknik ekspositori dan dramatik. Tokoh utama menampilkan gradasi karakter yang lebih leluasa karena ruang yang besar dalam cerita. Terdapat tiga tokoh yang mendominasi jalannya cerita. Tokoh ini menentukan perkembangan plot. Tiga tokoh tersebut yaitu, Jati Wesi, Tanaya Suma, dan Raras Prayagung. Raras merupakan pengendali dari tokoh-tokoh yang ada. Meskipun begitu, Jati Wesi yang menjadi tokoh paling utama dalam Aroma Karsa.

\section{Tokoh Tambahan}

Tokoh tambahan novel Aroma Karsa adalah Janirah Prayagung (nenek Raras Prayagung), Romo (ayah Raras Prayagung), Arya Jayadi (kekasih Suma sebelum muncul Jati), Khalil Batarfi (pemilik toko parfum Attarwala tempat Jati bekerja), Nurdin
Suroso (pemilik pabrik kompos, pengepul barang bekas, taman anggrek tempat Jati bekerja), Komandan Mada Utama (Petinggi Polsek Bantar Gebang), Anung (ayah asli Suma dari Dwarapala, desa tak kasat mata), Ambrik (ibu asli Suma dari Dwarapala, desa tak kasat mata), Prof. Sudjatmiko (Arkeolog, anggota tim ekspedisi pencarian Puspa Karsa yang pertama), Ibu Miko (Istri Prof. Sudjatmiko), Prof. Yustinus Herlambang (Arkeolog, pemimpin ekspedisi kedua pencarian Puspa Karsa), Dara (Istri Prof. Yustinus Herlambang), Prof. Iwan Satyana (Ahli botani, tim ekspedisi 2 pencarian Puspa Karsa), Kapten Jindra Mahameru (Kapten jenderal yang tergabung dalam tim ekspedisi kedua pencarian Puspa Karsa), Arini (Istri Kapten Jindra), Dirga (anak titipan untuk Jindra dan Arini), Sulati (Istri Khalil Batarfi yang mengurus Jati), Aan Durahman (korban pembunuhan yang ditemukan Jati di lautan sampah Bantar Gebang), Imas (Istri Aan Durahman), Fendi Siregar (pengacara Raras Prayagung atas sengketa tiruan parfum Jati kepada Kemara), Damar, Yanto, dan Burhan (teman Jati, staff kerja di toko Attarwala), Melinda (majikan Jati ketika jadi tukang kebun), Ningsih (teman Jati ketika jadi tukang kebun), Sarip (penjaga lapas tempat Anung ditahan), Rohali (tahanan di lapas), Bu Ida (istri Rohali), Bakrie (teman Jati di Pabrik Kompos), Wijah, Tiwi, dan Pak Jikun (pembantu Raras), Bunda Ratih, Utari, 
Aji, dan Indah (staf Kemara), Arnaund Baucard (pelatih Jati di Paris), Pasangan Ferrand (pengasuh Jati di Paris), Dokter Widagdo (dokter pribadi Raras untuk penciuman Suma), Galih (asisten pribadi Raras), Pucang, Sinom, Elar Manyura (Banaspati di Desa Dwarapala), Hanif (mantan ekspasukan khusus ekspedisi pertama pencarian Puspa Karsa), Istri Hanif, Mbah Jo (juru kunci Gunung Lawu), Hyang Arimong (sosok harimau penjaga Dwarapala), Mahesa Guning (Raja Kerajaan Majapahit), Puspa Karsa (bunga jahat yang mempengaruhi kehendak manusia).

\section{Latar (Setting)}

Latar Tempat

Secara garis besar latar tempat yang terdapat dalam novel Aroma Karsa karya Dee Lestari adalah Kota Yogyakarta, Kota Jakarta, TPA Bantar Gebang, Kota Bekasi, Grasee, Provence, Prancis, Kota Solo, Kabupaten Karanganyar, dan Gunung Lawu.

\section{Latar Waktu}

Latar waktu yang digunakan dalam novel Aroma Karsa terdiri dari latar waktu parsial. Latar parsial dapat digunakan menjadi dua kelompok melalui kata-kata yang langsung merujuk pada waktu dan kalimat yang diasosiasikan pada waktu. Secara garis besar, latar waktu terjadinya cerita dalam novel Aroma Karsa adalah tahun 1960-an, ketika Raras berusia 18 tahun, ketika Raras berusia 25 tahun, ketika Raras berusia 58 tahun, dan 26 tahun sebelum ekspedisi kedua dilaksanakan.

\section{Latar Sosial}

Latar sosial yang diceritakan dalam novel Aroma Karsa adalah kehidupan masyarakat di Indonesia. Latar sosial masyarakat Indonesia yang diceritakan pengarang merupakan tentang latar belakang beberapa tokoh dan tempat. Latar sosial masyarakat Jawa yang memiliki latar kejawen digunakan dalam novel ini.

\section{Latar Suasana}

Suasana sedih, pilu, duka, dan sunyi terdapat dalam cerita Aroma Karsa. Suasana itu tergambar ketika Raras Prayagung datang menemui dan menemani Janirah, neneknya yang sedang sekarat dan ketika Anung hendak melakukan prosesi Gurah Rudira kepada Ambrik.

\section{Sudut Pandang}

Sudut pandang adalah cara yang digunakan oleh pengarang untuk memosisikan diri dalam sebuah cerita. Sudut pandang yang digunakan pengarang dalam novel Aroma Karsa adalah pengarang serba tahu atau sudut pandang orang ketiga serba tahu atau omniscient narratif yang dapat menceritakan segalanya atau memasuki berbagai peran dengan bebas. Pengarang tidak fokus pada satu tokoh cerita saja, tetapi semua tokoh mendapatkan penonjolan. 


\section{Nilai dan Amanat}

Nilai Religius

Nilai religius berhubungan dengan kesatuan bersama Tuhan YME. Nilai religius dalam novel Aroma Karsa ditunjukkan melalui berbagai peristiwa. Salah satu peristiwa yang menunjukkan kedekatan dengan Sang Pencipta adalah ketika Anung merapal beberapa mantra yang ada dalam kepercayaannya untuk prosesi Gurah Rudira Ambrik. Selain itu, nilai religius juga ditunjukkan melalui kepercayaan di Desa Dwarapala yang mempercayai Empu Smarakandi adalah dewa yang memimpin Batarawana. Para pengikut Empu sangat patuh terhadap perintahnya.

Nilai Sosial

Menjaga Kelestarian Alam

Novel Aroma Karsa sangat keras membandingkan dunia yang ada di Bumi dan dunia yang ada di Desa Dwarapala, desa tak kasat mata. Aroma Karsa membandingkan dunia manusia yang penuh kekejaman, boros, dan tak ramah lingkungan. Kebiasaan keluarga Raras yang serba mewah hingga menyumbang ribuan sampah berbanding terbalik dengan keadaan warga Dwarapala yang makan sebutuhnya dan cinta lingkungan. Dwarapala sengaja disembunyikan agar manusia tidak tamak hingga merusak alam. Empu Smarakandi sangat melindungi Dwarapala saat Raras dan rombongan.
Membantu Orang Tua

Ketulusan seorang anak mencintai kedua orang tua merupakan sebuah kewajiban sekali pun bukan orang tua kandung. Sebagai seorang manusia sudah seharusnya membantu orang yang lebih tua dari kita apabila mereka membutuhkan bantuan. Membantu orang tua merupakan wujud kebaktian seorang anak. Meskipun bukan anak kandung, Jati dengan tulus membantu Umi mencuci piring-piring jamuan makan malam waktu itu.

Menghormati Orang Tua

Sikap menghormati kepada orang tua merupakan sebuah nilai baik dalam kehidupan seorang manusia. Sudah selayaknya sebagai manusia memiliki rasa hormat kepada siapa pun orang yang lebih tua dari kita. Menunduk sembari mengucapkan salam merupakan sebuah wujud menghormati kepada orang yang lebih tua. Begitulah yang dilakukan beberapa tentara ketika Mbah Jo tiba di Vila Raras. Begitupun yang dilakukan Suma kepada tim ekspedisi ketika berkumpul membahas perjalanan memburu Puspa Karsa. Suma menyalami satu persatu orang yang ada sebagai rasa hormat.

\section{Nilai Kepribadian}

Keteguhan

Nilai keteguhan ditunjukkan melalui tokoh Raras yang divonis cacat seumur hidup. Raras seumur hidup akan berada di kursi roda karena

BASASTRA Jurnal Bahasa, Sastra, dan Pengajarannya

Volume 9 Nomor 1, April 2021, P-ISSN 2302-6405, 2E-ISSN 2714-9765 
kejadian 26 tahun lalu di Dwarapala. Raras mendapat serangan mahkluk Dwarapala saat melakukan ekspedisi pencarian Puspa Karsa pertama.

\section{Kegigihan}

Terdapat nilai kegigihan dalam novel Aroma Karsa. Nilai kegigihan tersebut ditunjukkan oleh tokoh Raras. Semenjak ia ditinggal pergi selamanya oleh nenek dan ayahnya, ia menjadi wanita yang kuat. Raras mampu membuat perusahaan Kemara yang hampir mati ketika dipimpin ayahnya bangkit lagi hanya dalam waktu 5 tahun.

\section{Teguh Pendirian}

Nilai teguh pendirian dalam novel Aroma Karsa ditunjukkan melalui tokoh Jati. Sikap teguh pendirian tersebut digambarkan ketika Jati menolak untuk bekerja dieksploitasi habis-habisan dengan Nurdin meskipun diiming-imingi banyak uang.

\section{Kerja Keras}

Nilai kerja keras dalam novel Aroma Karsa ditunjukkan melalui tokoh Jati. Jati merupakan sosok yang banyak memiliki pekerjaan dan mampu mengerjakan tugasnya dengan baik di setiap tempat kerja

\section{Hubungan Antarunsur Novel Aroma Karsa Karya Dee Lestari Hubungan Tokoh dengan Tema}

Tema utama cerita Aroma Karsa adalah aroma. Pengarang menghadirkan tokoh Jati dan Suma untuk menyampaikan tema aroma tersebut. Jati dan Suma dihadirkan pengarang secara penuh untuk membawakan tema cerita Aroma Karsa yaitu, aroma.

\section{Hubungan Tokoh dengan Latar}

Hubungan tokoh Janirah dengan latar tempat yang ada di Keraton Yogyakarta. Selain hubungan tokoh dengan latar tempat, terdapat pula hubungan tokoh dengan latar waktu.

\section{Hubungan Tokoh dengan Alur}

Terdapat tokoh Mbah Jo yang melarang tim ekspedisi untuk naik ke Gunung Lawu. Namun, larangan itu dihiraukan oleh Raras. Hal itulah yang membuat alur cerita Aroma Karsa menjadi berkembang.

\section{Hubungan Latar dengan Alur}

Latar dan alur memiliki hubungan timbal balik dan saling mendukung dalam novel Aroma Karsa. Latar erat kaitannya dengan waktu, tempat, dan suasana yang akan memengaruhi alur suatu cerita. Terdapat hubungan latar dengan alur. Penggambaran suasana ruangan tempat Janirah sekarat mengingat kembali ke masa-masa zaman dahulu kala. Penggambaran tersebut sekaligus menjadikan pengantar awal cerita Aroma Karsa pada tahap paparan.

\section{Hubungan Latar dengan Tema}

Latar juga memiliki hubungan dengan tema dalam novel Aroma 
Karsa. Latar memengaruhi pemilihan tema atau sebaliknya, tema memengaruhi pemilihan latar sehingga mendukung cerita dalam novel Aroma Karsa. Hubungan latar tempat di TPA Bantar Gebang dengan tema utama aroma yaitu, aroma sampah. Pemilihan latar TPA Bantar Gebang sangat mendukung dengan tema yang diangkat dalam novel Aroma Karsa.

\section{Pemanfaatan Analisis Struktural} Novel Aroma Karsa karya Dee Lestari sebagai Materi Ajar Sastra Kelas XII SMA

Berdasarkan data yang sudah diperoleh melalui hasil analisis dan juga penelitian wawancara dengan informan mengenai novel Aroma Karsa karya Dee Lestari dapat disimpulkan bahwa novel ini dapat dimanfaatkan sebagai materi ajar sastra kelas XII SMA. Novel Aroma Karsa karya Dee Lestari dapat dimanfaatkan sebagai materi ajar sastra kelas XII SMA karena telah memenuhi beberapa kriteria pemanfaatan materi ajar, meliputi kevalidan, kebermanfaatan, kemenarikan, keutuhan, dan kebermaknaan. Pemanfaatan novel Aroma Karsa karya Dee Lestari sebagai materi ajar dapat melalui penggunaan metode jigsaw, talking sticking, dan penugasan mandiri. Langkah-langkah pemanfaatan meliputi (1) pembentukan kelompok belajar siswa, (2) kemudian masingmasing kelompok dibentuk tim ahli sejumlah unsur intrinsik, (3) tim ahli bergabung dengan tim ahli kelompok lain, (4) tim ahli bertugas menggali informasi dari kelompok lain, kemudian menginformasikan ke kelompoknya sendiri, (5) kemudian setiap kelompok mempresentasikan melalui penunjukkan metode talking sticking. Penggunaan novel Aroma Karsa sebagai materi ajar dapat diterapkan dalam pembelajaran karena mengandung nilai-nilai yang baik untuk siswa. Hal tersebut sesuai dengan kompetensi inti dan kompetensi dasar yang tercantum dalam kurikulum yang terbaru, yaitu kurikulum 2013 serta kesesuaiannya dengan tingkat kemampuan siswa. Pemanfaatan analisis struktural dalam novel Aroma Karsa karya Dee Lestari melalui penggunaan data dan hasil dari penelitian ini sebagai contoh dan referensi oleh guru bagi peserta didik. Guru tidak perlu membedah atau mencari bukti penjelasan terkait unsur intrinsik dalam novel, melainkan dapat menggunakan data-data yang telah dipaparkan dalam penelitian ini, seperti halnya dalam menjelaskan unsur tema, guru dapat menggunakan hasil temuan dalam skripsi ini sebagai penunjang materi dalam pembelajaran menganalisis isi novel. Misalnya, tema dalam novel Aroma Karsa adalah aroma. Guru dalam penyampaian tema aroma tersebut dapat menggunakan data berupa kutipan hasil catatan lapangan unsur tema sebagai bukti ketika menjelaskan tema kepada peserta didik. Begitu pula dengan unsur lainnya, seperti alur, latar, 
penokohan, sudut pandang, dan amanat.

\section{SIMPULAN}

Berdasarkan hasil analisis dan pembahasan terhadap novel Aroma Karsa karya Dee Lestari, dapat diambil simpulan bahwa analisis unsur intrinsik novel Aroma Karsa karya dee Lestari meliputi tema, alur, tokoh, latar, sudut pandang, dan amanat. Melalui hasil analisis unsur intrinsik novel Aroma Karsa karya Dee Lestari dapat disimpulkan bahwa setiap unsur yang terdapat dalam novel Aroma Karsa karya Dee Lestari memiliki hubungan dan tidak dapat berdiri sendiri. Unsur-unsur dalam novel Aroma Karsa karya Dee Lestari memiliki hubungan yang saling mendukung. Hubungan yang terjadi antarunsur intrinsik tersebut dapat dipahami dan dinikmati oleh pembaca sehingga isi novel tersampaikan dengan baik. Hubungan tersebut meliputi, hubungan antara tokoh dengan tema, tokoh dengan latar, tokoh dengan alur, latar dengan alur, latar dengan tema.

Berdasarkan data yang sudah diperoleh melalui hasil analisis dan juga penelitian wawancara dengan informan mengenai novel Aroma Karsa karya Dee Lestari dapat disimpulkan bahwa novel ini dapat dimanfaatkan sebagai materi ajar sastra kelas XII SMA. Novel Aroma Karsa karya Dee Lestari dapat dimanfaatkan sebagai materi ajar sastra kelas XII SMA karena telah memenuhi beberapa kriteria pemanfaatan materi ajar, meliputi kevalidan, kebermanfaatan, kemenarikan, keutuhan, dan kebermaknaan. Pemanfaatan novel Aroma Karsa karya Dee Lestari sebagai materi ajar dapat melalui penggunaan metode jigsaw, talking sticking, dan penugasan mandiri. Langkah-langkah pemanfaatan meliputi (1) pembentukan kelompok belajar siswa, (2) kemudian masingmasing kelompok dibentuk tim ahli sejumlah unsur intrinsik, (3) tim ahli bergabung dengan tim ahli kelompok lain, (4) tim ahli bertugas menggali informasi dari kelompok lain, kemudian menginformasikan ke kelompoknya sendiri, (5) kemudian setiap kelompok mempresentasikan melalui penunjukkan metode talking sticking. Penggunaan novel Aroma Karsa sebagai materi ajar dapat diterapkan dalam pembelajaran karena mengandung nilai-nilai yang baik untuk siswa. Hal tersebut sesuai dengan kompetensi inti dan kompetensi dasar yang tercantum dalam kurikulum yang terbaru, yaitu kurikulum 2013 serta kesesuainnya dengan tingkat kemampuan siswa.

Pemanfaatan analisis struktural dalam novel Aroma Karsa karya Dee Lestari melalui penggunaan data dan hasil dari penelitian ini sebagai contoh dan referensi oleh guru bagi peserta didik. Guru tidak perlu membedah atau mencari bukti penjelasan terkait unsur intrinsik dalam novel, melainkan dapat menggunakan data-data yang 
telah dipaparkan dalam penelitian ini, seperti halnya dalam menjelaskan unsur tema, guru dapat menggunakan hasil temuan dalam skripsi ini sebagai penunjang materi dalam pembelajaran menganalisis isi novel. Misalnya: tema dalam novel Aroma Karsa adalah aroma. Guru dalam penyampaian tema aroma tersebut dapat menggunakan data berupa kutipan hasil catatan lapangan unsur tema sebagai bukti ketika menjelaskan tema kepada peserta didik. Begitu pula dengan unsur lainnya, seperti alur, latar, penokohan, sudut pandang, dan amanat.

\section{REFERENSI}

Ali, I. (2014). The Structural Analysis of "Thirteen Reasions Why", a Novel by Jayasher. International Journal of Linguistics, Literature and Culture (LinquaIJLC), 1 (3), 70-82.

Alwi, H. (2002). Telaah Bahasa dan Sastra. Jakarta: Yayasan Obor Indonesia.
Emzir, S. (2016). Teori dan Pengajaran Sastra. Jakarta: Raja Grafindo Persada.

Jabrohim. (2014). Teori Penelitian Sastra. Yogyakarta: Pustaka Pelajar.

Nurgiyantoro, B. (2012). Teori Pengakjian Fiksi. Yogyakarta: Gajah Mada University Press.

Prameswari, W. D., Waluyo, H. J., \& Waluyo, B. (2018). Analisis Struktural Genetik Novel Bekisar Merah karya Ahmad Tohari dan Relevansinya sebagai Materi Pembelajaran Sastra di SMA. BASASTRA: Jurnal Penelitian Bahasa, Sastra Indonesia dan Pengajarannya, 6 (1), 268-278.

Yanti, T. \& May, R. B. (2016). Korelasi antara Kemampuan Memahami Isi Novel dengan Kemampuan Memahami Unsur Intrinsik terhadap Hasil Belajar Apresiasi Sastra Siswa SMA Negeri 1 Ampibado Kecamatan Ampibado Kabupaten Parigi Moutong. E-journal Bahasantodea, 4 (1), 87-95. 